\title{
Dalton Trans
}

\section{ARTICLE}

Received 00th January 20xx,

Accepted 00th January 20xx

DOI: $10.1039 / x 0 x \times 00000 x$

www.rsc.org/

\section{Introduction}

$C_{3}$-symmetric, tripodal ligands are used extensively as auxiliary ligands in single-site transition metal homogeneous catalysis and biomimetic systems. ${ }^{1-6}$ One of the major classes of these are tris-pyrazolyl borates (Figure 1a), which combine ease of synthesis with the ability to tune the steric and electronic character of the donor set by the introduction of electrondonating or electron-accepting substituents into the pyrazolyl ring units. ${ }^{7}$

An emerging but less well developed strategy for tuning ligands is the substitution of the bridgehead atom itself for other main group elements, with the potential not only for tuning the electronic character of the ligand but also the ligand bite in a systematic way. Our interest in this area has been in the tris-2-pyridyl family of ligands. The majority of studies in the past three decades have concerned neutral frameworks containing lighter, non-metallic bridgehead atoms $Y\left(2-\mathrm{py}^{\prime}\right)_{3}(\mathrm{Y}$ $=\mathrm{CR}, \mathrm{COR}, \mathrm{CH}, \mathrm{N}, \mathrm{P}, \mathrm{P}=\mathrm{O} ; 2-\mathrm{py}^{\prime}=$ an unsubstituted or substituted 2-pyridyl group) (e.g., Figure $1 \mathrm{~b}) .{ }^{8}$ More recently,

\footnotetext{
Chemistry Department. Cambridge University, Lensfield Road, Cambridge CB2 1EW (U.K.).Email: dsw1000@cam.ac.uk

${ }^{b .}$ Anorganisch-Chemisches Institut, Heidelberg University, Im Neuenheimer Feld 270,69120 Heidelberg (Germany)

GIR MIOMeT-IU Cinquima-Química Inorgánica, Facultad de Ciencias, Campus Miguel, Delibes, Universidad de Valladolid 47011 Valladolid, Spain. E-mail: raul.garcia.rodriguez@uva.es.

Electronic Supplementary Information (ESI) available: NMR spectroscopic and X ray characterisation. CCDC: $1833558-1833563$. DOI: 10.1039/x0xx00000x
}

however, attention has turned to the effects of incorporating more metallic Group $13,{ }^{9} 14^{10,11}$ and $15^{12}$ bridgeheads. ${ }^{13}$ These isoelectronic metallic relatives now span almost the entire range of $p$-block elements, from anionic aluminate ligands (e.g., inset to Figure 1, A), ${ }^{9}$ through to the heaviest counterpart containing a $\mathrm{Bi}^{\mathrm{III}}$ bridgehead (inset to Figure $\left.1, \mathrm{C}\right){ }^{12}$ We have shown recently that changing the bridgehead atom can have significant effects on both the coordination chemistry and reactivity of tris(2-pyridyl) ligands. For example, the increasing Lewis acidity of the elements as Group 15 is descended can impact dramatically on the ligand coordination mode as well as the $\sigma$-donor character of the ligand frameworks, introducing the potential for modulation of the structures and catalytic activity of metal complexes. ${ }^{12}$

Heavier Group 14 ligands of this type can be divided into two classes, neutral element-IV ligands of the type $[R E(2-$ $\left.\left.\mathrm{py}^{\prime}\right)_{3}\right]^{10}$ and element-II anions of the type $\left[\mathrm{E}\left(2-\mathrm{py}^{\prime}\right)_{3}\right]^{-11} .{ }^{11}$ Although Zeckert and coworkers have developed the coordination chemistry of the latter in a number of key studies, there is currently a surprising lack of structural data available on the element-IV oxidation state ligands [RE(2py $\left.)_{3}\right] .{ }^{10}$ Although there are reports of the coordination and supramolecular chemistry of bis(2-py) and tris(4-py) $\mathrm{Si}(\mathrm{IV})$ ligands ${ }^{14}$ and some early reports of the synthesis of tris(2-py) ligands, ${ }^{15}$ there are no structurally characterised examples of complexes of Ge(IV) tris(2-pyridyl) ligands [RGe(2-py') $)_{3}$ and only one example for the Si(IV) ligands [RSi(2-py') $)_{3}$, [MeSi(2- 
py) ${ }_{3} \operatorname{LiX}(X=\mathrm{Cl} / \mathrm{Br})$, containing the neutral [MeSi(2-py) $)_{3}$ ligand (2-py = unsubstituted 2-pyridyl) (inset to Figure 1, B). ${ }^{10 \mathrm{c}}$

In the current paper we set out with the simple aim of expanding knowledge of the coordination chemistry of $\mathrm{Si}(\mathrm{IV})$ tris(2-pyridyl) ligands. Entry into this system was facilitated by the synthesis of the new $\mathrm{Si}(\mathrm{IV})$ ligand [PhSi(6-Me-2-py) ${ }_{3}$ ] which was then used to obtain a range of (the first) transition metal complexes containing this type of donor. The synthesis, singlecrystal X-ray structures and selected solution dynamics of the new complexes $\left[\left\{\mathrm{PhSi}(6-\mathrm{Me}-2-\mathrm{py})_{3}\right\} \mathrm{CuCH}_{3} \mathrm{CN}\right]\left[\mathrm{PF}_{6}\right]$, [ $\{\mathrm{PhSi}(6-$ Me-2-py $\left.\left.)_{3}\right\} \mathrm{CuCH}_{3} \mathrm{CN}\right]\left[\mathrm{CuCl}_{2}\right], \quad\left[\left\{\mathrm{PhSi}(6-\mathrm{Me}-2-\mathrm{py})_{3}\right\} \mathrm{CoCl}_{2}\right]$, $\left[\left\{\mathrm{PhSi}(6-\mathrm{Me}-2-\mathrm{py})_{3}\right\} \mathrm{FeCl}_{2}\right]$ and $\left[\left\{\mathrm{PhSi}(6-\mathrm{Me}-2-\mathrm{py})_{3}\right\} \mathrm{Mo}(\mathrm{CO})_{3}\right]$ are described.
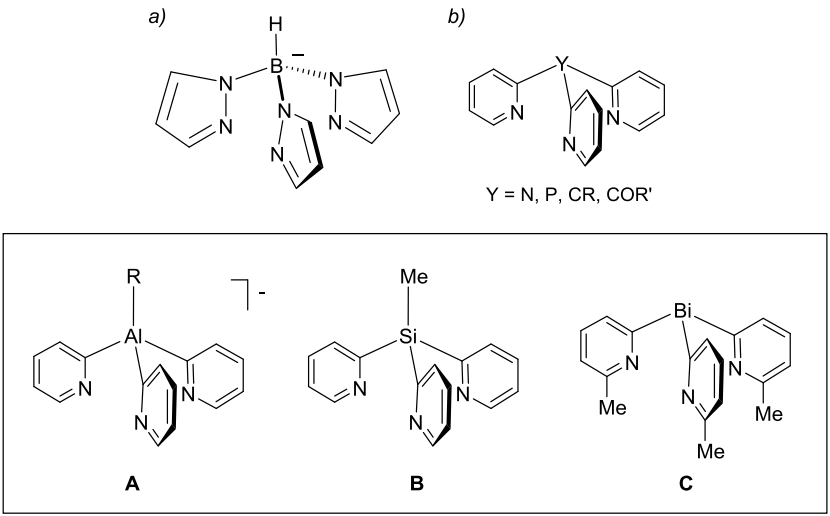

Figure 1 a) An unsubstituted tris-pyrazolyl-borate anion, b) the family of neutral unsubstituted tris (2-pyridyl) ligands containing non-metal bridgeheads. The inset shows three previously reported examples of tris(2-pyridyl) ligands spanning the range of more metallic bridgehead arrangements.

\section{Results and Discussion}

In previous work, we have found that the main obstacle to developing this area is the low yielding synthesis of unsubstituted tris(2-pyridyl) ligands from 2-lithio-pyridine and $\mathrm{RSiCl}_{3}$. As a result, the only coordination compound obtained so far in this area has been [MeSi(2-py $)_{3} \mathrm{LiCl}$, which was isolated in low yield (Scheme 1a). ${ }^{10 c}$, However, a clue to a way around this problem is provided by an early study which reported that the 6-bromo-substituted $\mathrm{Si}(\mathrm{IV})$ ligand [MeSi(6$\mathrm{Br}-2-\mathrm{py})_{3}$ ] can be obtained in $54 \%$ yield from the reaction of $\mathrm{MeSiCl}_{3}$ and lithiated 2,6-dibromo-pyridine. ${ }^{15 a}$ We recently showed that 6-methyl substitution at the pyridyl substituents not only leads to cleaner lithiation of the corresponding 2bromo-pyridine, but also stabilises the tris(2-pyridyl) products themselves by suppressing the reductive elimination of bipyridine. Thus, for example, whereas in situ reaction of unsubstituted 2-lithio-py with $\mathrm{BiCl}_{3}$ or $\mathrm{SbCl}_{3}$ could not be used to prepare the $\mathrm{Bi}(2-\mathrm{py})_{3}$ or $\mathrm{Sb}(2-\mathrm{py})_{3}$ ligands, the reaction involving 6-Me-2-py gave $\mathrm{Bi}(6-\mathrm{Me}-2-\mathrm{py})_{3}$ and $\mathrm{Sb}(6-\mathrm{Me}-2-\mathrm{py})_{3}$ in good yields. ${ }^{12}$ In the current study, we were able to obtain the new Si(IV) ligand [PhSi(6-Me-2-py) $)_{3}$ (1) in high yield (82\%) from the reaction of $\mathrm{PhSiCl}_{3}$ with 6-Me-2-Li-py in thf (Scheme $1 \mathrm{~b})$, providing gram-quantities for the further investigation of coordination chemistry. In contrast, the reaction between unmethylated 2-lithio-pyrdine and $\mathrm{PhSiCl}_{3}$ yields a mixture of products, as is apparent from the ${ }^{1} \mathrm{H}$ NMR spectrum of the crude reaction mixture. In addition, in the case of $\mathbf{1}$ we were able to remove all $\mathrm{LiCl} / \mathrm{LiBr}$ byproducts by extraction of the crude reaction mixture with toluene (the previously reported complex $\left[\mathrm{MeSi}(2-\mathrm{py})_{3}\right] \mathrm{LiCl}_{0.8} \mathrm{Br}_{0.2}$ being crystallized from thf). ${ }^{10 \mathrm{c}}$

Elemental analysis confirms that unlike the previously reported Si(IV) system, no lithium halide coordination occurs for 1 in crystalline samples. This is further confirmed by the single-crystal $\mathrm{X}$-ray structure, which shows a $C_{3}$-symmetric molecular arrangement in the solid state in which the pyridyl$\mathrm{N}$ atoms are orientated towards the Si(IV) bridgehead atom (Figure 2a). The absence of $\mathrm{LiX}(\mathrm{X}=\mathrm{Cl}, \mathrm{Br})$ coordination in 1 presents a technical advantage (in addition to the high yield of the ligand) because there is no need to separate LiX from reaction products after transfer of the ligand to other metal centres. It can be noted also that although $\mathbf{1}$ is prepared under inert-atmosphere conditions, it is in fact air-stable and only hygroscopic. Molecules of $\mathbf{1}$ are paired up in the lattice, forming a 'sextuple embrace' in which the three pyridyl rings of each molecule are interdigitate (Figure $2 b$ ). ${ }^{16}$

a)
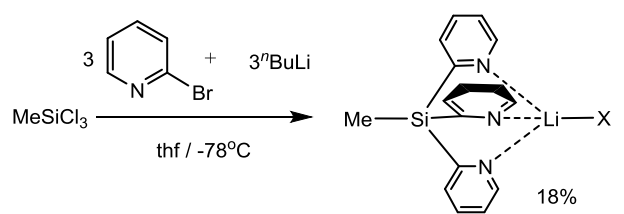

b)

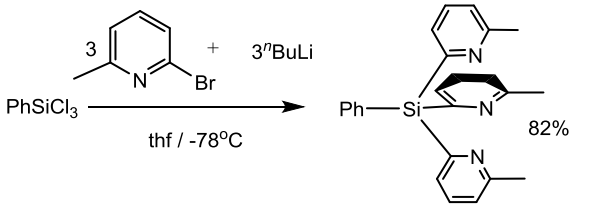

Scheme 1 a) Synthesis of the previous ligand [MeSi(2-py) $)_{3}$, as the LiX complex (X $=0.2 \mathrm{Br} / 0.8 \mathrm{Cl})$ and $\mathrm{b}$ ) the closely related synthesis of $\left[\mathrm{PhSi}(6-\mathrm{Me}-2-\mathrm{py})_{3}\right]$ ligand (1).

a)

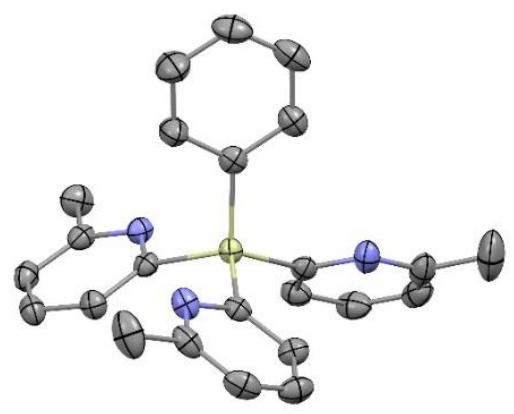

b)

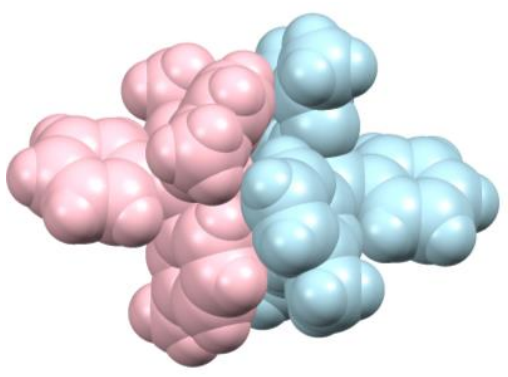

This journal is (C) The Royal Society of Chemistry 20xx 
Figure 2 a) Molecular structure of the ligand 1 showing displacement ellipsoids at $50 \%$ probability, with $\mathrm{H}$ atoms omitted; b) the 'sextuple embrace' of two molecules in the lattice. Selected bond lengths $(\AA)$ and angles $\left({ }^{\circ}\right)$ : $S i-C_{\text {phen }}$ $1.879(2), \mathrm{Si}-\mathrm{C}_{\text {pyridyl }}$ range $1.882(2)-1.886(2), \mathrm{C}_{\text {pyridyl }}-\mathrm{Si}-\mathrm{C}_{\text {pyridyl }}$ range $107.25(8)$ $110.18(8)$, Si- $\mathrm{C}_{\text {pyridyl }} \mathrm{N}$ range $114.15(13)-114.61(14)$. Colour key, Si (yellow), nitrogen (blue).

Coordination studies of $\mathbf{1}$ with a range of transition meta salts and organometallics were undertaken. The overall results of these studies are shown in Scheme 2.

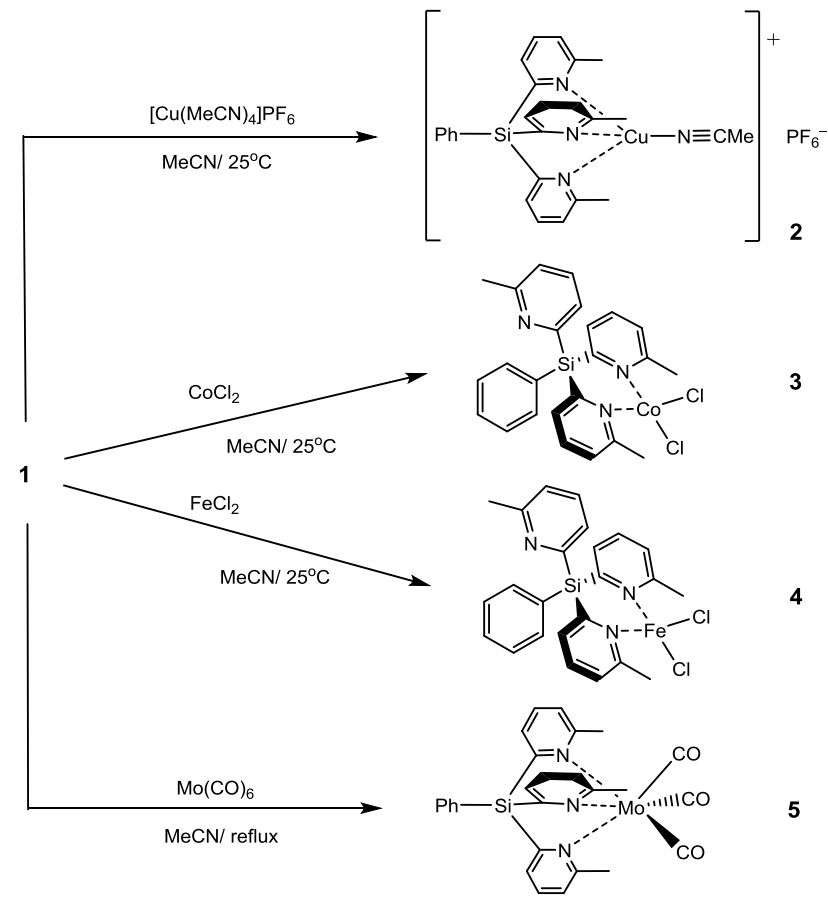

Scheme $\mathbf{2}$ The coordination of ligand $\mathbf{1}$ to various transition metals in the current study Yields of crystalline complexes 2, 31\%; 3, 70\%; 4, 65\%; 5, 21\%.

The new complexes $\left[\left\{\mathrm{PhSi}(6-\mathrm{Me}-2-\mathrm{py})_{3}\right\} \mathrm{CuCH}_{3} \mathrm{CN}\right] \mathrm{PF}_{6}$ (2), [\{PhSi(6-Me-2-py $\left.\left.)_{3}\right\} \mathrm{CoCl}_{2}\right](3),\left[\left\{\mathrm{PhSi}(6-\mathrm{Me}-2-\mathrm{py})_{3}\right\} \mathrm{FeCl}_{2}\right]$ (4) and $\left[\left\{\mathrm{PhSi}(6-\mathrm{Me}-2-\mathrm{py})_{3}\right\} \mathrm{Mo}(\mathrm{CO})_{3}\right] \quad$ (5) were characterised by elemental $\left(\mathrm{C}, \mathrm{H}, \mathrm{N}\right.$ ) analysis and (where appropriate) ${ }^{1} \mathrm{H}$ and ${ }^{13} \mathrm{C}$ NMR spectroscopy. The single-crystal X-ray structures were also obtained (see Table 1, ESI).

The reaction of $\left[\mathrm{Cu}\left(\mathrm{CH}_{3} \mathrm{CN}\right)_{4}\right] \mathrm{PF}_{6}$ with 1 in $\mathrm{CH}_{3} \mathrm{CN}$ at room temperature gives the crystalline complex [ $\mathrm{PhSi}(6-\mathrm{Me}-2$ py) $\left.\left.{ }_{3}\right\} \mathrm{CuCH}_{3} \mathrm{CN}\right] \mathrm{PF}_{6}(2)$ in $31 \%$ isolated yield. The $\mathrm{C}_{3}$-symmetric coordination of $\mathrm{Cu}^{\prime}$ is apparent from the changes in the chemical shifts of the ${ }^{1} \mathrm{H}$ and ${ }^{13} \mathrm{C}$ NMR spectra for $\mathbf{2}$ compared to 1 and the presence of only one 6-Me-2-py environment. The single-crystal $\mathrm{X}$-ray structure of $\mathbf{2}$ shows that it is an ionseparated complex containing $\left[\left\{\mathrm{PhSi}(6-\mathrm{Me}-2-\mathrm{py})_{3}\right\} \mathrm{CuCH}_{3} \mathrm{CN}\right]^{+}$ cations (Figure 3 ) and $\mathrm{PF}_{6}{ }^{-}$anions. The tris-coordination of all three of the $\mathrm{N}$-atoms of the pyridyl rings to various metal centres is common for the tris-pyridyl family of ligands and the previously reported ion-separated complexes [ $\{\mathrm{RC}(6-\mathrm{Me}-2-$ py) $\left.\left.{ }_{3}\right\} \mathrm{CuCH}_{3} \mathrm{CN}\right] \mathrm{PF}_{6}(\mathrm{R}=\mathrm{H}, \mathrm{Me})$, containing C-bridged pyridyl ligands, are closely related to $\mathbf{2}$ (containing C-bridged analogues of ligand $\mathbf{1}$, with the same 6-Me-2-py substituents). ${ }^{17}$ There are noticeable effects in changing the bridgehead atom from the smaller $\mathrm{C}$ - to the larger Si-atom. In particular, the $\mathrm{Cu}-\mathrm{N}_{\text {pyridyl }}$ bonds in the cation of 1 [2.061(4)$2.121(4) \AA]$ are on average longer than those in the $[\{R C(6-\mathrm{Me}-$ 2 -py $\left.\left.)_{3}\right\} \mathrm{CuCH}_{3} \mathrm{CN}\right]^{+}$cations $[1.993(8)-2.088(7) \AA]^{16}{ }^{16}$ There is also a large expansion of the internal $\mathrm{N}_{\text {pyridyl }}-\mathrm{Cu}-\mathrm{N}_{\text {pyridyl }}$ coordination angles from $90.23(9)-91.8(3)^{\circ}$ in the $[\{\mathrm{RC}(6-\mathrm{Me}-2$ py) $\left.\left.{ }_{3}\right\} \mathrm{CuCH}_{3} \mathrm{CN}\right]^{+}$cations $^{16}$ to $97.65(16)-100.65(16)^{\circ}$ in the cation of 1 . Both of these changes can be traced to the increase in the bridgehead $\mathrm{Si}-\mathrm{C}$ bond length in the $\mathrm{Si}$ analogue.

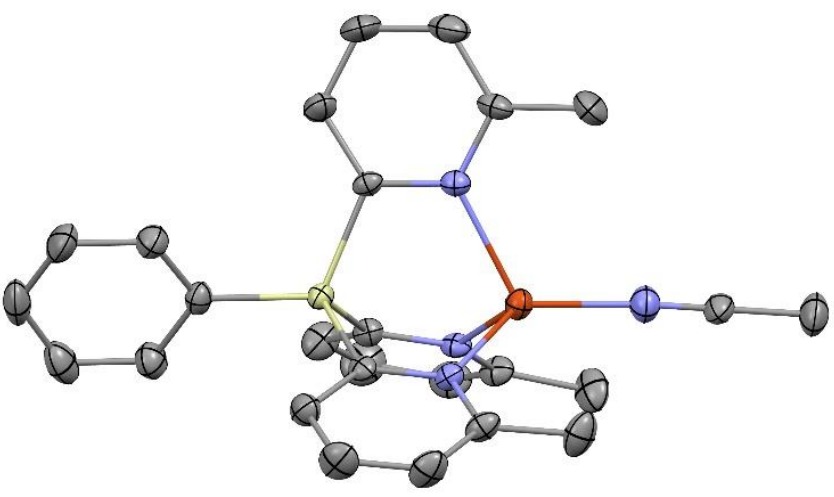

Figure 3 Structure of the $\left[\left\{\mathrm{PhSi}(6-\mathrm{Me}-2-\mathrm{py})_{3}\right\} \mathrm{CuCH}_{3} \mathrm{CN}\right]^{+}$cation of 2 showing displacement ellipsoids at $50 \%$ probability, with $\mathrm{H}$ atoms omitted. Selected bond lengths $(\AA)$ and angles $\left({ }^{\circ}\right)$ : Si- $C_{\text {phenyl }} 1.871(5)$, Si- $C_{\text {pyridyl }}$ range $1.888(5)-1.892(5), \mathrm{Cu}$ $\mathrm{N}_{\text {pyridyl }}$ range 2.061(4)-2.121(4), Cu- $\mathrm{N}_{\text {MeCN }} 1.936(4), C_{\text {pyridyl }}-\mathrm{Si}-\mathrm{C}_{\text {pyridyl }}$ range 104.0(2)$110.0(2)$, Si- $C_{\text {pyridyl }}-\mathrm{N}$ range 114.0(3)-117.4(3), $\mathrm{N}_{\text {pyridyl }}-\mathrm{Cu}-\mathrm{N}_{\text {pyridyl }}$ 97.65(16)-100.65(16). Colour key, Cu (red), Si (yellow), N (blue).

Interestingly, the 1 : 1 stoichiometric reaction of 1 with $\mathrm{Cu}^{\prime \prime} \mathrm{Cl}_{2}$ in $\mathrm{CH}_{3} \mathrm{CN}$ initially forms a green solution characteristic of $\mathrm{Cu}^{\prime \prime}$ before slowly turning yellow at room temperature. The yellow all-Cu' complex $\left[\left\{\mathrm{PhSi}(6-\mathrm{Me}-2-\mathrm{py})_{3}\right\} \mathrm{Cu}^{\prime} \mathrm{CH}_{3} \mathrm{CN}\right]^{+} \mathrm{Cu}^{\prime} \mathrm{Cl}_{2}{ }^{-}$is the only solid product that could be isolated (Scheme 3). Since this was obtained in low yield it was only characterised by single-crystal X-ray crystallography (see ESI). The reduction of $\mathrm{Cu}^{\prime \prime}$ in the presence of metal or semi-metal bridged tris-pyridyl ligand frameworks has been seen before and is probably coupled to the reductive elimination of $6,6^{\prime}$-di-methylbipyridine, although the precise mechanism involved is not certain. For example, the attempted coordination of the $\mathrm{Sn}^{\mathrm{IV}}$ tris-pyridyl ligand $\left[{ }^{n} \mathrm{BuSn}(2-\mathrm{py})_{3}\right]$ to $\mathrm{Cu}^{\prime \prime}$ results in a $\mathrm{Cu}^{\prime}$ complex. ${ }^{10 \mathrm{a}}$ This redox instability contrasts with C-bridged trispyridyl ligands which can be transferred intact to the $\mathrm{Cu}^{2+}$ cation without breakdown of the ligand framework, ${ }^{17}$ e.g., as in the case of the complex $\left.\left[\mathrm{HC}(6-\mathrm{Me}-2-\mathrm{py})_{3}\right\} \mathrm{CuBr}_{2}\right]$. $^{18}$

The $1: 1$ stoichiometric reactions of $\mathrm{CoCl}_{2}$ and $\mathrm{FeCl}_{2}$ with 1 give clean transfer of the transition metal ions into the corresponding complexes $\left[\left\{\mathrm{PhSi}(6-\mathrm{Me}-2-\mathrm{py})_{3}\right\} \mathrm{CoCl}_{2}\right]$ (3) (70\%) and $\left[\left\{\mathrm{PhSi}\left(6-\mathrm{Me}-2-\mathrm{py}_{3}\right\} \mathrm{FeCl}_{2}\right]\right.$ (4) (65\%), respectively. 

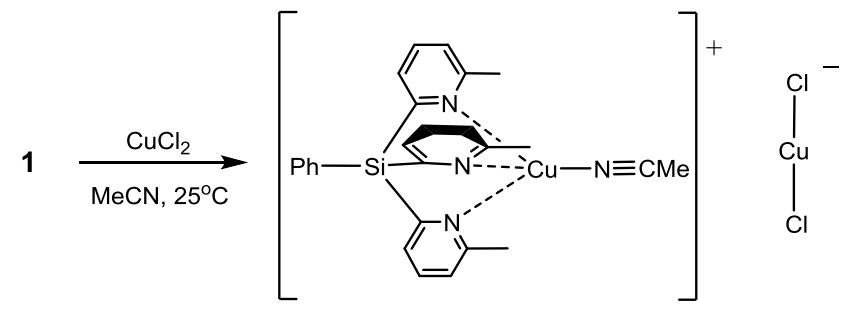

Scheme 3 Formation of the all-Cu' complex from $\mathbf{1}$ and $\mathrm{Cu}^{\prime \prime} \mathrm{Cl}_{2}$. For the structure of the complex see the ESI.

Satisfactory elemental analyses were obtained for both compounds. However, room-temperature ${ }^{1} \mathrm{H}$ spectroscopy proved unhelpful in their characterisation owing to the paramagnetic nature of the high-spin $d^{6}$ and $d^{7}$ electronic configurations of the transition metal ions and the presence of a fluxional process (described later). Unambiguous characterisation was made by single-crystal X-ray diffraction. Both complexes are isostructural (Figure 4), consisting of molecules in which the tris-pyridyl ligand $\mathbf{1}$ adopts a bidentate coordination mode in which only two of the three $\mathrm{N}$-atoms are bonded to the transition metal ions.

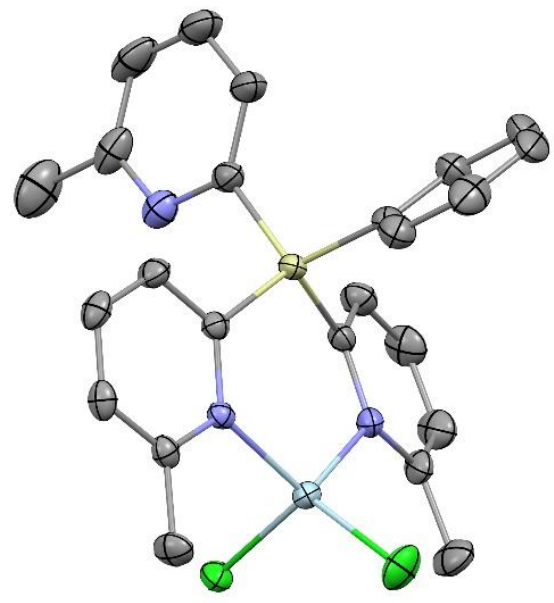

Figure 4 Molecular structure of $\left[\left\{\mathrm{PhSi}(6-\mathrm{Me}-2-\mathrm{py})_{3}\right\} \mathrm{CoCl}_{2}\right]$ (3); [ $\{\mathrm{PhSi}(6-\mathrm{Me}-2$ py) ${ }_{3} \mathrm{FeCl}_{2}$ ] (4) is isostructural in the solid state. Displacement ellipsoids are shown at $50 \%$ probability and $\mathrm{H}$ atoms are omitted. Selected bond lengths $(\AA)$ and angles $\left({ }^{\circ}\right)$ : 3, Si- $C_{\text {phenyl }} 1.866(2)$, Si- $C_{\text {pyridyl }}$ range $1.872(2)-1.885(2)$, Co- $\mathrm{N}_{\text {pyridyl }}$ range 2.0505(18)-2.0589(19), Co-Cl 2.2339(7)-2.2623(6), $C_{\text {pyridyl }}-S_{-}-C_{\text {pyridyl }}$ range 105.67(11) $115.78(10)$, Si- $\mathrm{C}_{\text {pyridy }}-\mathrm{N}$ range $119.81(17)-122.80(16)$ (coordinating pyridyl groups), Si$\mathrm{C}_{\text {pyridyl }} \mathrm{N}$ 113.26(17) (non-coordinating pyridyl group), N-Co-N $110.47(7), \mathrm{Cl}-\mathrm{Co}-\mathrm{Cl}$ $118.50(3) .4$, Si- $C_{\text {phenyl }} 1.866(3)$, Si- $C_{\text {pyridyl }}$ range $1.874(3)-1.884(3)$, Fe- $\mathrm{N}_{\text {pyridyl }}$ range 2.106(2)-2.118(2), Fe-Cl range 2.2486(8)-2.2885(7), $\mathrm{C}_{\text {pyridyl}}-\mathrm{Si}-\mathrm{C}_{\text {pyridyl }}$ range 105.60(12)$117.09(10)$, Si- $C_{\text {pyridy }}-\mathrm{N}$ range $119.90(18)-122.11(17)$ (coordinating pyridyl groups), Si$\mathrm{C}_{\text {pyridyl }} \mathrm{N}$ 113.57(18) (non-coordinating pyridyl group), N-Fe-N 108.88(8), Cl-Fe-Cl 124.58(3). Colour key, Si (yellow), N (blue), Co (light blue), Cl (green).

There are no closely related analogues of $\mathbf{3}$ and $\mathbf{4}$ containing C-bridged tris-pyridyl ligands, the closest relatives being the $2: 1$ 'sandwich' complexes $\left[\left\{\mathrm{MeC}(2-\mathrm{py})_{3}\right\}_{2} \mathrm{M}\right]^{2+}(\mathrm{M}=$ $\mathrm{Co}$ ",Fe"). ${ }^{19}$ However, the bis-coordination of two of the $\mathrm{N}$ atoms of ligand $\mathbf{1}$ found in both complexes is the same as that observed for the isoelectronic $\mathrm{P}(6-\mathrm{Me}-2-\mathrm{py})_{3}$ ligand in the complex $\left[\left\{\mathrm{P}(6-\mathrm{Me}-2-\mathrm{py})_{3}\right\} \mathrm{FeCl}_{2}\right]$, which has a very similar structural arrangement. ${ }^{20}$ The reasons behind this biscoordination of the metal cations in $\mathbf{3}$ and $\mathbf{4}$, rather than triscoordination in the potential alternative ionisation isomer $\left[\left\{\mathrm{P}(6-\mathrm{Me}-2-\mathrm{py})_{3}\right\} \mathrm{FeCl}\right]^{+}[\mathrm{Cl}]^{-}$, are likely to stem from the combined effects of the presence of sterically constraining 6Me substituents (which also make the formation of 2 : 1 sandwich complexes unfavourable with small metal cations) and the greater strength of $\mathrm{M}-\mathrm{Cl}$ bonds compared to $\mathrm{M}-\mathrm{N}$ bonds. The metal- $\mathrm{N}$ bond lengths in $\mathbf{3}$ and $\mathbf{4}$ are as expected for tetrahedral $\mathrm{Co}^{2+}$ and $\mathrm{Fe}^{2+}$ cations. ${ }^{21}$

As noted before, the ${ }^{1} \mathrm{H}$ NMR spectra of 3 and 4 at $298 \mathrm{~K}$ were uninformative due to unusually broad resonances, even for paramagnetic complexes of $\mathrm{Co}^{\text {"I }}$ and Fe". However, reducing the temperature of solutions of $\mathbf{3}$ and $\mathbf{4}$ in toluene results in significant sharpening of the ${ }^{1} \mathrm{H}$ resonances for both compounds. The sharpening of the spectra strongly indicates that a dynamic (fluxional) process is occurring. In the case of $\mathbf{3}$, gradual sharpening of the signals is observed between 353 and $253 \mathrm{~K}$ to show eventually the same $2: 1$ desymmetrization of the 6-Me-2-py substituents that is present in the solid-state structure. At the same time, the line-widths of the $\mathrm{Ph}$ resonances remain unchanged in this temperature interval, showing that fluctionality of the pyridyl groups alone is responsible for the observed effect. Additional information is obtained from the temperature-dependent behaviour of $\mathbf{4}$ which shows similar behaviour as $\mathbf{3}$ between 230 and $298 \mathrm{~K}$. However, increasing the temperature above $298 \mathrm{~K}$ also results in sharpening of the 6-Me- and 2-py resonances into a $\mathrm{C}_{3}-$ symmetric arrangement containing only one 6-Me-2-py environment. This behaviour is consistent with an intramolecular fluxional process involving precession of the bis-coordinating pyridyl groups in both complexes (Scheme 4).
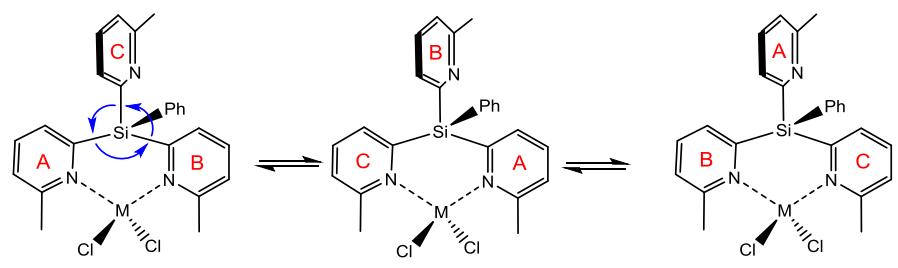

Scheme 4 Precession of the pyridyl groups, as a potential explanation for the fluxional behaviour of $\mathbf{3}$ and $\mathbf{4}(\mathrm{M}=\mathrm{Co}, \mathrm{Fe})$.

The low-temperature $(230 \mathrm{~K}){ }^{1} \mathrm{H}$ NMR signals of the coordinated pyridyl groups in $\mathbf{3}$ and $\mathbf{4}$ can be assigned using DFT calculated spin-densities. ${ }^{22}$ However, the correlation of the calculated NMR shifts using Fermi-contact and orbital shifts alone is not satisfactory (Figure S9, ESI). EXSY (2-D Exchange) NMR spectroscopy allows the assignment of $\mathrm{H}^{2}$ of non-coordinated pyridyl at $+12 \mathrm{ppm}$ (exchange peak with $\mathrm{H}^{2}{ }_{\mathrm{c}}$ at $\delta-28 \mathrm{ppm}$ ). This atom is seven bonds away from the paramagnetic centre and therefore no Fermi-contact shift contributes to the observed NMR value, only orbital and pseudocontact shifts. Using the molecular structure and a magnetic axis that bisects the $\mathrm{N}-\mathrm{Fe}-\mathrm{N}$ angle gives an axial magnetic anisotropy $\left(\Delta \chi_{\mathrm{ax}}\right)$ of $7 \times 10^{-32} \mathrm{~m}^{3}$ for 4 (see Figure S11, ESI). In a similar way $\Delta \chi_{\text {ax }}$ was determined for $3\left(8 \times 10^{-32} \mathrm{~m}^{3}\right)$. Including both Fermi-contact and pseudo-contact shifts leads to a much better agreement with the experimental ${ }^{1} \mathrm{H} N M R$ spectrum (Figure 5). The anisotropy of $\mathbf{4}$ compares well with a known 4-coordinate $\mathrm{Fe}^{2+}$ complex ${ }^{23}$ whereas in octahedral $\mathrm{Co}^{2+}$ compounds much larger anisotropies compared to $\mathbf{3}$ have been observed. ${ }^{24}$ 


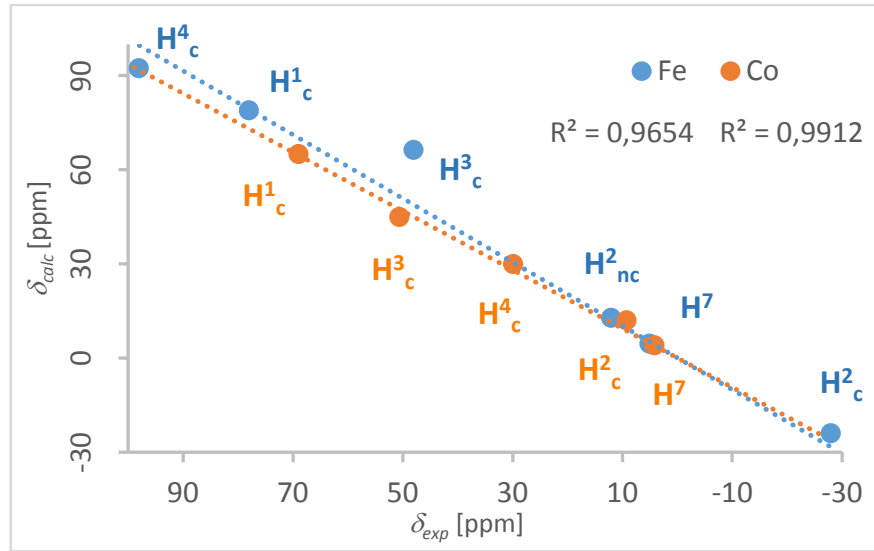

Figure 5 Correlation of experimental with calculated ${ }^{1} \mathrm{H}$ NMR shifts of $\mathbf{3}$ and $\mathbf{4}$ (at $230 \mathrm{~K}$ ), considering orbital, Fermi-contact and pseudo-contact shifts. $\mathrm{H}^{\mathrm{x}}{ }_{\mathrm{c}}$ and $\mathrm{H}^{\mathrm{x}}{ }_{\mathrm{n}}$ denotes atoms of coordinated and non-coordinated pyridyl units, respectively. For the numbering scheme see Figure 7

The 1 : 1 stoichiometric reaction of $\mathrm{Mo}(\mathrm{CO})_{6}$ with 1 in $\mathrm{MeCN}$ at reflux produces the complex [ $\mathrm{PhSi}(6-\mathrm{Me}-2-$ py) $\left.{ }_{3}\right\} \mathrm{Mo}(\mathrm{CO})_{3}$ ] (5) in $21 \%$ yield after crystallisation from $\mathrm{CH}_{2} \mathrm{Cl}_{2}$ (as the $\mathrm{CH}_{2} \mathrm{Cl}_{2}$ mono-solvate). As in the case of diamagnetic $\mathbf{1}$, significant changes in the chemical shifts in the ${ }^{1} \mathrm{H}$ and ${ }^{13} \mathrm{C}$ NMR spectra provided an initial indication of the formation of the complex. The $\mathrm{C}_{3}$-symmetric, tridentate coordination mode of the $\left[\mathrm{PhSi}(6-\mathrm{Me}-2-\mathrm{py})_{3}\right]$ is also obvious from the presence of only one 2-py environment in the ${ }^{1} \mathrm{H}$ NMR spectrum. The solidstate structure of $\mathbf{5}$ shows the expected tris-coordination of $\mathbf{1}$ to a $\mathrm{Mo}(\mathrm{CO})_{3}$ unit within its molecular arrangement (Figure 6). This is similar to that of the previously reported complex $\left[\left\{{ }^{n} \mathrm{BuSn}(2-\mathrm{py})_{3}\right\} \mathrm{Mo}(\mathrm{CO})_{3}\right]$, containing a Sn-bridged 2-pyridyl ligand. $^{10 \mathrm{~b}}$

The IR spectrum of solid $\mathbf{5}$ shows two CO stretching bands at 1893 and $1750 \mathrm{~cm}^{-1}$. This can be compared to the solid-state IR spectra reported previously for $\left[\left\{\mathrm{HC}(2-\mathrm{py})_{3}\right\} \mathrm{Mo}(\mathrm{CO})_{3}\right](1897$ and $\left.1769 \mathrm{~cm}^{-1}\right)^{25}$ and $\left.\left[{ }^{n} \mathrm{BuSn}(2-\mathrm{py})_{3}\right\} \mathrm{Mo}(\mathrm{CO})_{3}\right]$ (1900 and (averaged) $1763 \mathrm{~cm}^{-1}$ ). ${ }^{10 \mathrm{~b}}$ Unfortunately it is impossible on this basis to delineate the effect of the electronegativity of the bridgehead atom from the additional effect of the electrondonating 6-Me groups present in 5, since the decrease in electronegativity going down Group 14 and the electrondonating Me substituents should both result in greater $\sigma$ donor character. This said, it appears that $\mathbf{5}$ has similar $\sigma$ donor/ $\pi$-acceptor properties to the $\left[\mathrm{HC}(2-\mathrm{py})_{3}\right]$ and $\left[{ }^{n} \mathrm{BuSn}(2-\right.$ py) ${ }_{3}$ ] ligands.

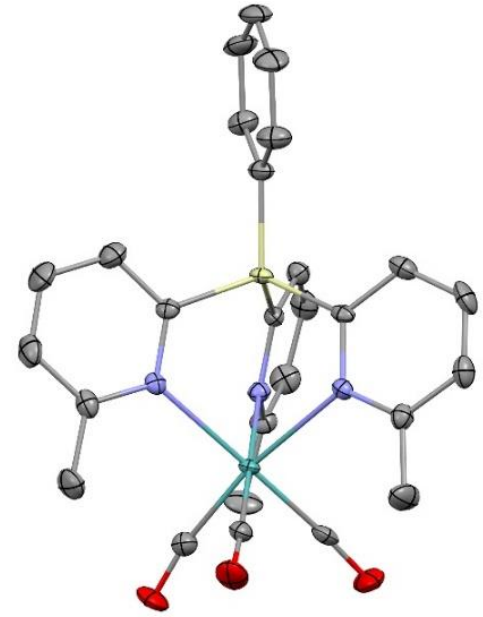

Figure 6 Molecular structure of $\left[\left\{\mathrm{PhSi}(6-\mathrm{Me}-2-\mathrm{py})_{3}\right\} \mathrm{Mo}(\mathrm{CO})_{3}\right](5)$ in the solvate 5. $\mathrm{CH}_{2} \mathrm{Cl}_{2}$, showing displacement ellipsoids at $50 \%$ probability. $\mathrm{H}$-atoms and the $\mathrm{CH}_{2} \mathrm{Cl}_{2}$ lattice solvent are omitted. Selected bond lengths $(\AA)$ and angles $\left({ }^{\circ}\right)$ : $\mathrm{Si}-\mathrm{C}_{\text {phenyl }}$ 1.876(3), Si- $C_{\text {pyridyl }}$ range 1.870(3)-1.874(3), Mo- $\mathrm{N}_{\text {pyridyl }}$ range 2.343(2)-2.424(2), Mo-C range 1.921(3)-1.933(3), $\mathrm{C}_{\text {pyridyl }}-\mathrm{Si}-\mathrm{C}_{\text {pyridyl }}$ range $103.96(13)-112.88(13), \mathrm{Si}-\mathrm{C}_{\text {pyridy }}-\mathrm{N}$ range 115.9(2)-120.4(2), $\quad \mathrm{N}_{\text {pyridyl-Mo- }} \mathrm{N}_{\text {pyridyl }}$ 86.87(8)-90.05(8), C-Mo-C range 79.91(13)86.28(13). Colour key, Mo (green), Si (yellow), N (blue), O (red).

\section{Conclusions}

In conclusion, substitution at the 6-position of the pyridyl ring units makes the synthesis of the resulting [PhSi(6-Me-2-py)] ligand much more amenable and produces usable amounts for further coordination studies. This has allowed access to the first examples of transition metal complexes of this type of $\mathrm{Si}^{\mathrm{IV}}$ tris-pyridyl ligand. Synthetic studies show that, while these ligands function similarly to their C-bridged relatives, they nonetheless exhibit some redox instability, depending on the metal coordinated; a characteristic of related $\mathrm{Sn}^{\mathrm{IV}}$ tris-pyridyl ligands.

This study forms part of our on-going work designed to investigate how changing the main group bridgehead atoms can be used to modulate the reactivity of tris-pyridyl and related tripodal ligand arrangements, in particular. Future studies will explore the applications of ligands of this type in a range of catalytic reactions.

\section{Acknowledgements}

We thank The Leverhulme Trust (Grant for DSW and RG-R, postdoctoral funding for ALC), The Spanish MINECO-AEI and The EU (ESF) for a Ramon y Cajal contract (RG-R, RYC-201519035) and The Cambridge Trust (Vice Chancellor Scholarship for AJP).

\section{Conflicts of Interest}

There are no conflicts of interest. 


\section{Experimental Section}

\section{General Experimental Techniques}

All experiments were carried out on a Schlenk-line under a nitrogen atmosphere or with the aid of a $\mathrm{N}_{2}$-filled glove box (Saffron type $\alpha$ ). MeCN and $\mathrm{CH}_{2} \mathrm{Cl}_{2}$ were dried over $\mathrm{CaH}_{2}$. THf and toluene were distilled over $\mathrm{Na}$ /benzophenone. 6-Methyl2-bromo-pyridine was distilled over $\mathrm{CaH}_{2}$ and stored over $4 \AA$ molecular sieves. $\mathrm{PhSiCl}_{3}$ was acquired from Aldrich Chemical Company and distilled prior to use. ${ }^{1} \mathrm{H},{ }^{13} \mathrm{C}\left\{{ }^{1} \mathrm{H}\right\}$ and ${ }^{31} \mathrm{P}\left\{{ }^{1} \mathrm{H}\right\}$ NMR spectra were recorded on a Bruker Avance 400 QNP or Bruker Avance $500 \mathrm{MHz}$ cryo spectrometer. All spectra were recorded in $d_{8}$-toluene or $\mathrm{CD}_{3} \mathrm{CN}$ with $\mathrm{SiMe}_{4}\left({ }^{1} \mathrm{H}\right)$ or the toluene Me-peak as external and internal standards. Unambiguous assignments of NMR resonances were made on the basis of 2D NMR experiments $\left({ }^{1} \mathrm{H}-{ }^{1} \mathrm{H}\right.$ COSY, ${ }^{1} \mathrm{H}-{ }^{1} \mathrm{H}$ NOESY, ${ }^{1} \mathrm{H}_{-}{ }^{13} \mathrm{C} \mathrm{HMQC}$ and ${ }^{1} \mathrm{H}_{-}{ }^{13} \mathrm{C} \mathrm{HMBC}$ ). Figure 7 shows the labelling scheme for NMR assignments used throughout the Experimental Section. Elemental analysis was obtained using a Perkin Elmer 240 Elemental Analyser.

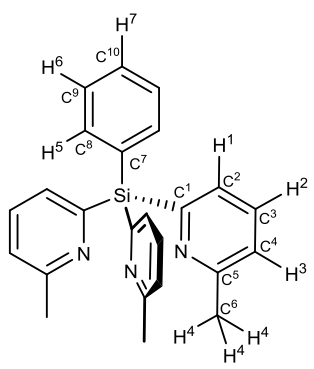

Figure 7 Showing the labelling scheme used for NMR spectra in the following characterisation and in Figure 5 in the main text.

\section{X-ray Crystallographic Studies.}

Data were collected for 1, 2, 3, 4 and 5 on a Bruker D8 QUEST Photon-100 diffractometer with an Incoatec I $\mu \mathrm{S}$ Cu microfocus source. The temperature was held at $180(2) \mathrm{K}$ using an Oxford Cryosystems $\mathrm{N}_{2}$ cryostat. Crystals were mounted directly from solution using perfluorohydrocarbon oil to prevent atmospheric oxidation, hydrolysis and solvent loss. Further details of data collection and refinements can be found in the ESI (Table S1). CCDC: 1833561 (1), 1833563 (2), 1833559 (3), $1833560(4), 1833562\left(5 . \mathrm{CH}_{2} \mathrm{Cl}_{2}\right), 1833558$ ([\{PhSi(6-Me-2py) $\left.\left.{ }_{3}\right\} \mathrm{Cu}^{\prime} \mathrm{CH}_{3} \mathrm{CN}\right]^{+} \mathrm{Cu}^{\prime} \mathrm{Cl}_{2}{ }^{-}$).

\section{Synthesis of compounds 1-5.}

Synthesis of 1: 2-Bromo-6-methyl pyridine $(2.28 \mathrm{ml}, 20 \mathrm{mmol})$ was dissolved in $40 \mathrm{ml}$ of thf. To this ${ }^{n} \mathrm{BuLi}(12.5 \mathrm{ml}, 20 \mathrm{mmol}, 1.6 \mathrm{M}$ in hexanes) was added dropwise at $-78^{\circ} \mathrm{C}$. The resulting dark orange solution was stirred for $3 \mathrm{~h}$ at $-78^{\circ} \mathrm{C}$. $\mathrm{PhSiCl}_{3}(1.4 \mathrm{~g}, 6.66 \mathrm{mmol})$ in 5 $\mathrm{ml}$ of thf was added dropwise to the dark red lithiated species. The resulting pale brown mixture was allowed to warm to room temperature. After stirring overnight, a dark brown solution with a light brown precipitate was formed. All volatiles were removed under vacuum and the resulting solid residue was extracted with 40 $\mathrm{ml}$ of warm toluene. The suspension was filtered through Celite to yield a clear-brown solution which was concentrated under vacuum until the precipitation of a white solid was observed, which was redissolved by gentle heating. Storage overnight at $-15^{\circ} \mathrm{C}$ yielded 1 as colourless needles suitable for X-ray crystallography. The product was isolated by filtration and storage of the mother liquor yielded a second crop of crystals. Combined yield $2.10 \mathrm{~g}$ (4.61 mmol, 82\%). Elemental analysis (\%) calcd. for 1: C 75.5, H 6.1, N 11.0 found: $\mathrm{C}$ 74.5, H 5.9, N 10.5. ${ }^{1} \mathrm{H}$ NMR $\left(25^{\circ} \mathrm{C}, \mathrm{d}_{8}\right.$-toluene, $\left.500.12 \mathrm{MHz}\right)$ : $\delta(\mathrm{ppm})=8.20(\mathrm{~d}, J=7.0 \mathrm{~Hz}, 2 \mathrm{H}, \mathrm{H}-5), 7.86(\mathrm{~d}, J=7.4 \mathrm{~Hz}, 3 \mathrm{H}, \mathrm{H}-1)$, $7.24(\mathrm{~m}, 3 \mathrm{H}, \mathrm{H}-6, \mathrm{H}-7), 7.11(\mathrm{t}, J=7.7 \mathrm{~Hz}, 3 \mathrm{H}, \mathrm{H}-2), 6.68(\mathrm{~d}, J=7.8 \mathrm{~Hz}$, $3 \mathrm{H}, \mathrm{H}-3), 2.40(\mathrm{~s}, 9 \mathrm{H}, \mathrm{H}-4) .{ }^{13} \mathrm{C}\left\{{ }^{1} \mathrm{H}\right\}$ NMR $\left(25^{\circ} \mathrm{C}, \mathrm{d}_{8}\right.$-toluene, 125.78 $\mathrm{MHz}): \delta(\mathrm{ppm})=162.7(\mathrm{C}-1), 157.9(\mathrm{C}-2), 136.7(\mathrm{C}-4), 134.3(\mathrm{C}-7)$, 133.6 (C-3), 129.8 (C-9), 129.0 (C-5) , 127.3 (C-8), 122.2 (C-10), 24.0 (C-6).

Synthesis of 2, 3 and 4: A Schlenk tube was charged with (6-Mepy) ${ }_{3} \mathrm{SiPh}(300 \mathrm{mg}, 0.78 \mathrm{mmol}, 1$ eq.) and 1 equivalent of the transition metal source $\left[\mathrm{Cu}(\mathrm{MeCN})_{4} \mathrm{PF}_{6}(314 \mathrm{mg}, 0.78 \mathrm{mmol})\right.$ for 2 $\mathrm{CoCl}_{2}(100 \mathrm{mg}, 0.78 \mathrm{mmol}, 1 \mathrm{eq})$ for $3,(100 \mathrm{mg}, 0.78 \mathrm{mmol})$ for 4 in a glove-box. The Schlenk tube was transferred to a vacuum line and $25 \mathrm{ml}$ of $\mathrm{CH}_{3} \mathrm{CN}$ was added. The resulting solution (yellow for 2 , green for $\mathbf{4}$ and $\mathbf{5}$ ) was stirred at room temperature overnight and then concentrated under vacuum until the precipitation of a solid was observed (yellow for $\mathbf{2}$ and $\mathbf{4}$, blue for $\mathbf{3}$ ). The solid was redissolved by gentle heating. Storage overnight at $-15{ }^{\circ} \mathrm{C}$ yielded crystals of $\mathbf{2}$ (yellow), $\mathbf{3}$ (blue) or $\mathbf{4}$ (yellow) suitable for X-ray crystallography which were isolated by filtration. For 2: Yield 152 $\mathrm{mg}(0.24 \mathrm{mmol}, 31 \%)$. Elemental analysis (\%) calcd. for 2: $\mathrm{C} \mathrm{49.5,} \mathrm{H}$ 4.2, $\mathrm{H}$ 8.9, found: $\mathrm{C} 49.2, \mathrm{H} 4.2, \mathrm{~N} 9.1 .{ }^{1} \mathrm{H}$ NMR $\left(25^{\circ} \mathrm{C}, \mathrm{CD}_{3} \mathrm{CN}\right.$, $500.12 \mathrm{MHz}): \delta(\mathrm{ppm})=8.08(\mathrm{~d}, J=6.9 \mathrm{~Hz}, 2 \mathrm{H}, \mathrm{H}-5), 7.78(\mathrm{t}, J=7.5$ $\mathrm{Hz}, 1 \mathrm{H}, \mathrm{H}-7), 7.72(\mathrm{~m}, 5 \mathrm{H}, \mathrm{H}-6, \mathrm{H}-2), 7.60$ (d, $J=7.5 \mathrm{~Hz}, 3 \mathrm{H}, \mathrm{H}-1)$, $7.40(\mathrm{~d}, J=7.8 \mathrm{~Hz}, 3 \mathrm{H}, \mathrm{H}-3), 2.83(\mathrm{~s}, 9 \mathrm{H}, \mathrm{H}-4), 1.99(\mathrm{~s}, 3 \mathrm{H}$, Acetonitrile). ${ }^{31} \mathrm{P}$ NMR $\left(25^{\circ} \mathrm{C}, \mathrm{CD}_{3} \mathrm{CN}, 202.48 \mathrm{MHz}\right): \delta(\mathrm{ppm})=-144.6$ (hpt, $\left.{ }^{1} \mathrm{~J}_{\mathrm{PF}}=705.69 \mathrm{~Hz}, \mathrm{PF}_{6}\right) .{ }^{13} \mathrm{C}\left\{{ }^{1} \mathrm{H}\right\}$ NMR $\left(25{ }^{\circ} \mathrm{C}, \mathrm{CD}_{3} \mathrm{CN}, 125.78\right.$ $\mathrm{MHz}): \delta(\mathrm{ppm})=160.2(\mathrm{C}-1), 158.6(\mathrm{C}-2), 148.9(\mathrm{C}-4), 136.7$ (C-7), 136.1 (C-3), 131.6 (C-9), 130.2 (C-5) , 128.9 (C-8), 125.3 (C-10), 24.7 (C-6). For 3: Yield $210 \mathrm{mg}(0.55 \mathrm{mmol}, 70 \%)$. Elemental analysis (\%) calcd. for 2: C 49.5, H 4.2, H 8.9, found: C 49.2, H 4.2, N 9.1. For 4: Yield $195 \mathrm{mg}(0.50 \mathrm{mmol}, 65 \%)$. Elemental analysis (\%) calcd. for 4: C $56.7, \mathrm{H} \mathrm{4.5}, \mathrm{N} 8.3$, found $\mathrm{C} 55.3, \mathrm{H} 4.5, \mathrm{~N} 8.8$. For details of the paramagnetic ${ }^{1} \mathrm{H}$ NMR studies of $\mathbf{3}$ and $\mathbf{4}$, see the ESI.

Synthesis of 5; A Schlenk tube was charged with PhSi(6-Me-py) (500 mg, $1.30 \mathrm{mmol}$ ) and $\mathrm{Mo}(\mathrm{CO})_{6}(343 \mathrm{mg}, 1.30 \mathrm{mmol}, 1 \mathrm{eq}$ ) inside a $\mathrm{N}_{2}$-filled glove box. The Schlenk tube was transferred to a vacuum line and $25 \mathrm{ml}$ of $\mathrm{CH}_{3} \mathrm{CN}$ was added. The resulting solution was brought to reflux overnight during which the colour changed to brown/red. The solvent was removed and the solid brown residue was dissolved in $25 \mathrm{ml}$ of dichloromethane and stirred for 2 hours. The solution was concentrated under vacuum until the precipitation of a red solid was observed, which was redissolved by gentle heating. Storage overnight at $-15^{\circ} \mathrm{C}$ yielded yellow crystals of 5. $\mathrm{CH}_{2} \mathrm{Cl}_{2}$ suitable for X-ray crystallography which were isolated by filtration. Isolation of this solvate under vacuum (1 bar) results in loss of $c a$. $0.5 \mathrm{CH}_{2} \mathrm{Cl}_{2}$ molecules per molecular unit, to give a final product with the formula $5.0 .5 \mathrm{CH}_{2} \mathrm{Cl}_{2}$. Yield $150 \mathrm{mg}(0.27 \mathrm{mmol}$, 21\%). Elemental analysis (\%) calcd. for $5.0 .5 \mathrm{CH}_{2} \mathrm{Cl}_{2} \mathrm{C} 54.7, \mathrm{H} 4.0, \mathrm{~N}$ 7.0; found, C 54.9, H 4.1, N 8.0. IR (Solid), CO stretch: $1893 \mathrm{~cm}^{-1}$ and $1750 \mathrm{~cm}^{-1} .{ }^{1} \mathrm{H}$ NMR $\left.\left(25^{\circ} \mathrm{C}, 500 \mathrm{MHz}^{\mathrm{CDCl}}\right)_{3}\right), \delta[\mathrm{ppm}]=8.06(\mathrm{~d}, J=$ $6.8 \mathrm{~Hz}, 2 \mathrm{H}, \mathrm{H}-5), 7.72(\mathrm{~m}, 3 \mathrm{H}, \mathrm{H}-6, \mathrm{H}-7), 7.50(\mathrm{~m}, 6 \mathrm{H}, \mathrm{H}-1, \mathrm{H}-2), 7.27$ (d, J $=8.9 \mathrm{~Hz}, 3 \mathrm{H}, \mathrm{H}-3), 3.34(\mathrm{~s}, 9 \mathrm{H}, \mathrm{H}-4)\left(\mathrm{CH}_{2} \mathrm{Cl}_{2}\right.$ also present at 5.3 (s)). ${ }^{13} \mathrm{C}$ NMR $\left(25^{\circ} \mathrm{C}, 125.78 \mathrm{MHz}, \mathrm{CDCl}_{3}\right), \delta[\mathrm{ppm}]=228.16(\mathrm{CO})$, 166.03 (C-1), 159.33 (C-2) , 137.01 (C-4), 134.35 (C-7), 131.56 (C-3), 130.13 (C-9), 129.21 (C-5), 128.44 (C-8), 126.24 (C-10), 29.04 (C-6).

\section{References}

1. P. Hofmann, L. H. Gade, Molecular Catalysis: Structure and Functional Design, WILEY VCH Verlag, Weinheim Germany, 2014.

2. C. Moberg, Angew. Chemie Int. Ed., 1998, 37, 248

3. C. Vogel, F. W. Heinemann, J. Sutter, C. Anthon, K. Meyer, Angew. Chemie Int. Ed., 2008, 47, 2681.

4. C. Dro, S. Bellemin-Laponnaz, R. Welter, L. H. Gade, Angew. Chemie Int. Ed., 2004, 43, 4479.

5. N. L. Lampland, M. Hovey, D. Mukherjee, A. D. Sadow, ACS Catal., 2015, 5, 4219.

6. A. G. Walden, A. J. M. Miller, Chem. Sci., 2015, 6, 2405-2410. 
7. S. Trofimenko, Chem. Rev., 1993, 93, 943-980

8. L. F. Szczepura, L. M. Witham, K. J. Takeuchi, Coord. Chem. Rev., 1998, 174, 5 .

9. F. Garcia, A. D. Hopkins, R. A. Kowenicki, M. McPartlin, M. C. Rogers, D. S. Wright, Organometallic, 2004, 23, 3884; 4, C. S. Alvarez, F. Garcia, S. M. Humphrey, A. D. Hopkins, R. A. Kowenicki, M. McPartlin, R. A. Layfield, R. Raja, M. C. Rogers, A. D. Woods, D. S. Wright, Chem. Commun., 2005 198; F. Garcia, A. D. Hopkins, R. A. Kowenicki, M. McPartlin, M. C. Rogers, J. S. Silvia, D. S. Wright, Organometallics, 2006, 25, 2561; T. H. Bullock W. T. K.Chan, D. S. Wright, Dalton Trans., 2009, 6709; T. H. Bullock, W. T. K. Chan, D. J. Eisler, M. Streib, D. S. Wright, Dalton Trans., 2009, 1046; R. Garcia-Rodriguez, H. R. Simmonds, D. S. Wright, Organometallics, 2014, 33, 7113; R. Garcia-Rodriguez, T. H. Bullock, M. McPartlin, D. S. Wright, Dalton Trans., 2014, 43, 14045; R. Garcia-Rodriguez, D. S. Wright, Chem. Eur. J., 2015, 21, 14949; R. Garcia-Rodriguez, S. Hanf, A. D. Bond, D. S. Wright, Chem. Commun., 2017, 53, 1225; R. Garcia-Rodriguez, D. S. Wright, Dalton Trans., 2018, 47, 2232.

10. a) M. A. Beswick, C. J. Belle, M. K. Davies, M. A. Halcrow, P. R. Raithby, A. Steiner, D. S. Wright, Chem. Commun., 1996, 2619; b) D. Morales, J. Perez, L. Riera, V. Riera, D. Miguel, Organometallics, 2001, 20, 4517; c) F. Garcia, A. D. Hopkins, S. M. Humphrey, M. McPartlin, M. C. Rogers, D. S. Wright, Dalton Trans., 2004, 361.

11. M. A. Beswick, M. K. Davies, P. R. Raithby, A. Steiner, D.S.Wright, Organometallics, 1997, 16, 1109; F. Reichart, M. Kischel, K. Zeckert, Chem. Eur. J., 2009, 15, 10018; K. Zeckert, S. Zahn, B. Kirchner, Chem. Commun., 2010, 46, 2838; K. Zeckert, Organometallics, 2013, 32, 1389; K. Zeckert, J. Griebel, R. Kirmse, M. Weiss, R. Denecke, Chem. Eur. J., 2013 19, 7718; K. Zeckert, Dalton Trans., 2012, 14, 14101; I. Schrader, K. Zeckert, S. Zahn, Angew. Chem., Int. Ed., 2014, 53, 13698.

12. A. J. Plajer, A. L. Colebatch, F. J. Rizzuto, P. Pröhm, A. D. Bond, R. GarciaRodriguez, D. S. Wright, Angew. Chem., in press.

13. For a general review of the area see H. R. Simmonds, D. S. Wright, Chem. Commun., 2012, 48, 8617.

14. M. Safa, M. C. Jennings, R. J. Puddephatt, Organometallics, 2012, 31, 3539; F. A. Cotton, E. V. Dikarev, M. A. Petrukhina, M. Schmitz, P. J. Stang, Inorg. Chem., 2002, 41, 2903.

15. a) J. E. Parks, B. E. Wagner, R. H. Holm, J. Organomet. Chem., 1973, 56, 53; b) F. Riedmiller, A. Jockisch, H. Schmidbauer, Organometallics, 1998 $17,4444$.

16. I. G. Dance and M. L. Scudder, Chem. Commun., 1995, 1039; I. G. Dance, M. L. Scudder, Dalton Trans., 1998, 1341; T. Steiner, J. Chem. Crystallogr., 1999, 29, 1235.

17. M. Kodera, Y. Kajita, Y. Tachi, K. Kano, Inorg. Chem., 2003, 42, 1193.

18. M. Kodera, Y. Tachi, T. Kita, H. Kobushi, Y. Sumi, K. Kano, M. Shiro, M. Koikawa, T. Tokii, M. Ohba, H. Okawa, Inorg. Chem., 2000, 39, 226.

19. A. Santoro, C. Sambiagio, P. C. McGowan, M. A. Halcrow, Dalton Trans., 2015, 44, 1060.

20. S. Hanf, R. Garcia-Rodriguez, A. D. Bond, E. Hey-Hawkins, D. S. Wright, Dalton Trans., 2016, 45, 276.

21. Search of the Cambridge Crystallographic Data Base, March 2018

22. P. Fernández, H. Pritzkow, J. J. Carbó, P. Hofmann, M. Enders, Organometallics, 2007, 26, 4402

23. M. Kruck, H. Wadepohl, M. Enders, L. H. Gade, Chem. Eur. J., 2013, 19, 1599.

24. V. V. Novikov, A. A. Pavlov, Y. V. Nelyubina, M.-E. Boulon, O. A. Varzatskii, Y. Z. Voloshin, R. E. P. Winpenny, J. Am. Chem. Soc., 2015, 137, 9792. 